\title{
Simulation of Continuous Tension Stringing Process of Conductor with Bending Stiffness Model
}

\author{
Chen Liu \\ China Electric Power Research \\ Institute \\ Beijing, China \\ Email: lc901013@sina.com
}

\author{
Jian Qin \\ China Electric Power Research \\ Institute \\ Beijing, China
}

\author{
Jiancheng Wan \\ China Electric Power Research \\ Institute \\ Beijing, China
}

\begin{abstract}
At present, there is no research on the calculation of tension variation of the conductor with bending stiffness model between the continuous span during tension stringing construction. Aiming at the typical terrain with large elevation difference in UHV project, a vector finite element method for calculating the tension of the conductor with bending stiffness model passes through the pulley in the process of tension stringing is proposed. The process of the wire rope under the action of the tractor pulling the conductor passes through the pulley continuously is realized. The variations of tension of tensioner and tractor, reaction force of pulley and envelope angle of the conductor passes through the pulley are obtained by simulation of tension stringing conditions such as 1 pulls 1,1 pulls 2 , etc, which provides reference for equipment selection for the tension stringing construction of mountain terrain with large elevation difference.
\end{abstract}

Keywords-transmission line, bending stiffness, conductor, tension stringing, vector finite element method, numerical simulation

\section{INTRODUCTION}

In the tension stringing process of UHV transmission line engineering, it is often faced with severe topographical conditions such as large elevation difference and large span, etc. During the construction, the tension is large and needs high control accuracy. Meanwhile, the working condition of conductor passes through the pulley is more complicated. At present, there is no relevant research on the tension variation of the conductor with bending stiffness model between the continuous span in the process of tension stringing [1-5]. Therefore, it is necessary to carry out numerical simulation on the continuous tension stringing process of conductor with bending stiffness model.

In this paper, the vector finite element method is used to calculate the tension variation of conductor under typical terrain with large elevation difference in UHV engineering [6], which provides technical support for tension stringing in terrain with large elevation difference.

\section{SiMULATION OF EQUIVALENT BENDING STIFFNESS OF CONDUCTOR}

The type of conductor is $8 \times \mathrm{JL} 1 / \mathrm{G} 2 \mathrm{~A}-1250 / 100$ aluminium cable steel reinforced, the cylindrical structure is used as the equivalent structure of the conductor with bending stiffness model. According to the simulation results of equivalent bending stiffness of $1250 \mathrm{~mm}^{2}$ large section conductor [7], equivalent bending stiffness $E I=113.678 \mathrm{~N} \cdot \mathrm{m}^{2}$ and tensile stiffness $E A=25090010 \mathrm{~N}$. Establish a simplified equivalent cylinder model, according to the formula:

$$
\begin{aligned}
& E I_{\text {cylinder }}=E \cdot \frac{\pi}{64} D^{4} \\
& E A_{\text {cylinder }}=E \cdot \frac{\pi}{4} D^{2}
\end{aligned}
$$

In the formula:

$E I$ is equivalent bending stiffness of conductor, $\mathrm{N} \cdot \mathrm{m}^{2}$;

$E A$ is tensile stiffness of conductor, $\mathrm{N}$;

$E$ is modulus of elasticity, GPa; $\mathrm{m}$

$D$ is the diameter of the simplified equivalent cylinder,

$A$ is the cross section area of the simplified equivalent cylinder, $\mathrm{m}^{2}$;

Thus:

$$
\begin{aligned}
& D=4 \sqrt{\frac{I}{A}} \\
& A=\frac{\pi D^{2}}{4}
\end{aligned}
$$

The equivalent structural parameters of the conductor are shown in the table I.

TABLE I. EQUIVALENT STRUCTURAL PARAMETERS OF THE CONDUCTOR

\begin{tabular}{|c|c|c|c|}
\hline $\begin{array}{c}\text { Modulus of } \\
\text { elasticity (GPa) }\end{array}$ & $\begin{array}{c}\text { Mass per unit } \\
\text { length } \mathbf{( k g} / \mathbf{m})\end{array}$ & $\begin{array}{c}\text { Diameter } \\
(\mathbf{m})\end{array}$ & $\begin{array}{c}\text { Cross section area } \\
\mathbf{( m}^{\mathbf{2}} \mathbf{)}\end{array}$ \\
\hline 440 & 4.252 & $8.514 \times 10^{-3}$ & $5.691 \times 10^{-5}$ \\
\hline
\end{tabular}

\section{VECTOR FINITE ELEMENT SIMULATION OF CONTINUOUS TENSION STRINGING PROCESS OF CONDUCTOR}

In the past, the force on the conductor passing through the suspension point was calculated directly in the tension stringing construction process, without considering the 
2019 Scientific Conference on Network, Power Systems and Computing (NPSC 2019)

tension change of the process of wire rope pulls conductor [8]. In order to better conform to the actual condition of tension stringing construction, the calculation model of wire rope pulls conductor is adopted. According to the vector finite element method proposed in references [6], the continuous tension stringing process of conductor is simulated.

\section{(1) Selection of tension stringing section}

According to the tower location details of an UHV transmission line project, the conductor length $L=6300 \mathrm{~m}$ is set for tension stringing, and the location of the tower pulley (span, elevation difference) are selected as shown in table II.

TABLE II. THE LOCATION OF THE TOWER PULLEY

\begin{tabular}{|l|l|l|}
\hline \multicolumn{1}{|c|}{ Tower number } & \multicolumn{1}{|c|}{ Span (m) } & Elevation difference (m) \\
\hline N4890 & 50643 & 750.1 \\
\hline N4891 & 51288 & 959.4 \\
\hline N4892 & 51797 & 1087.7 \\
\hline N4893 & 52488 & 1343.3 \\
\hline N4894 & 53003 & 1273.5 \\
\hline N4895 & 53897 & 1075.3 \\
\hline N4896 & 54732 & 955.7 \\
\hline N4897 & 55183 & 939.8 \\
\hline N4898 & 56175 & 1022.4 \\
\hline N4899 & 56542 & 1046.6 \\
\hline
\end{tabular}

(2) Analysis of simulation results

The traction mode is set as 1 pulls 1 (A wire rope pulls a conductor), 1 pulls 2 and 1 pulls 4 . The traction speed is set as $v=1.39 \mathrm{~m} / \mathrm{s}$ and $v=0.695 \mathrm{~m} / \mathrm{s}$.

Through simulation, the configuration of wire rope pulls conductor is obtained as shown in figure 1 , curves of tension of tensioner (point A) and tractor (point B) versus time are shown in figure 2 , curves of horizontal and vertical reaction force of pulley (point $\mathrm{O}$ ) versus time are shown in figure 3 , curves of envelope angle of the conductor passes through the pulley versus time are shown in figure 4.

1) 1 pulls $1, v=1.39 \mathrm{~m} / \mathrm{s}$

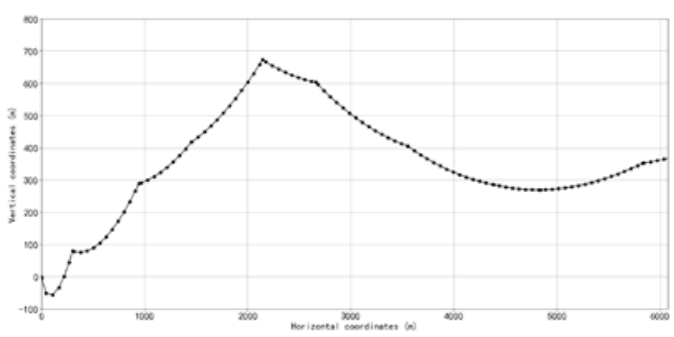

Fig. 1. Configuration of wire rope pulls conductor (traction speed $\mathrm{v}=$ $1.39 \mathrm{~m} / \mathrm{s}$, traction mode: 1 pulls 1 )

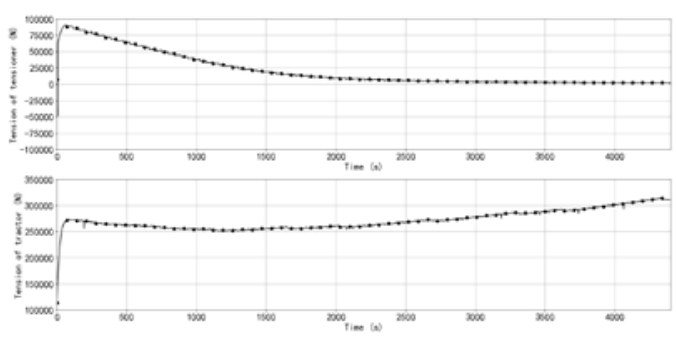

Fig. 2. Curves of tension of tensioner (point A) and tractor (point B) versus time (traction speed $\mathrm{v}=1.39 \mathrm{~m} / \mathrm{s}$, traction mode: 1 pulls 1 )

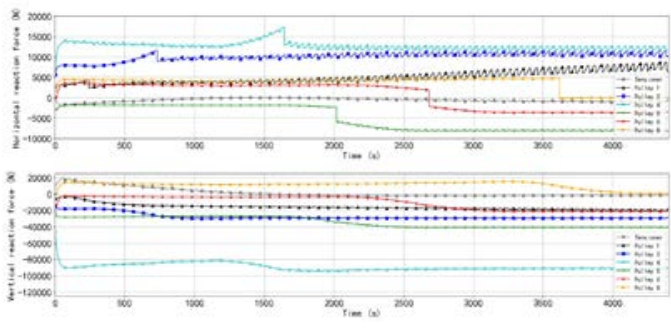

Fig. 3. Curves of horizontal and vertical reaction force of pulley (point $\mathrm{O}$ ) versus time (traction speed $\mathrm{v}=1.39 \mathrm{~m} / \mathrm{s}$, traction mode: 1 pulls 1 )

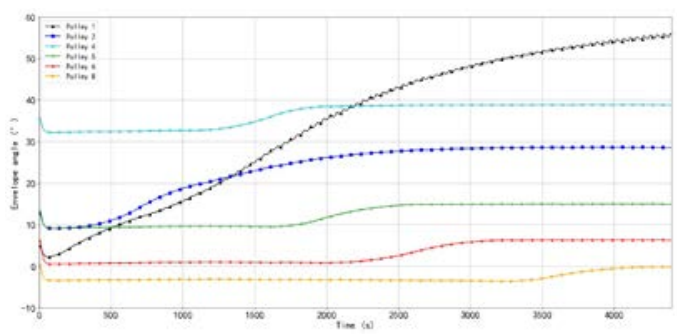

Fig. 4. Curves of envelope angle of the conductor passes through the pulley versus time (traction speed $\mathrm{v}=1.39 \mathrm{~m} / \mathrm{s}$, traction mode: 1 pulls 1 )

2) 1 pulls $2, v=1.39 \mathrm{~m} / \mathrm{s}$

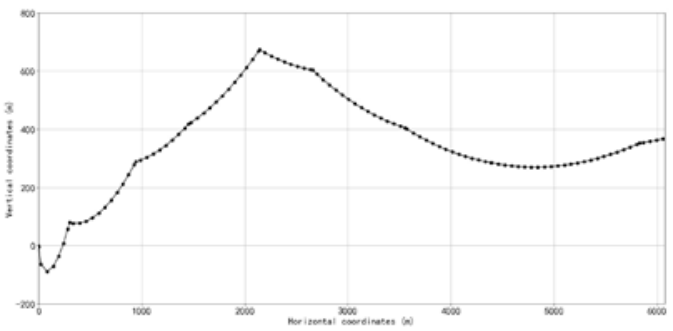

Fig. 5. Configuration of wire rope pulls conductor (traction speed $\mathrm{v}=$ $1.39 \mathrm{~m} / \mathrm{s}$, traction mode: 1 pulls 2 )

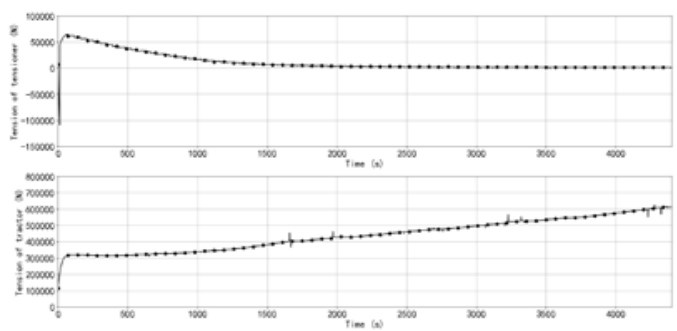

Fig. 6. Curves of tension of tensioner (point A) and tractor (point B) versus time (traction speed $\mathrm{v}=1.39 \mathrm{~m} / \mathrm{s}$, traction mode: 1 pulls 2 )

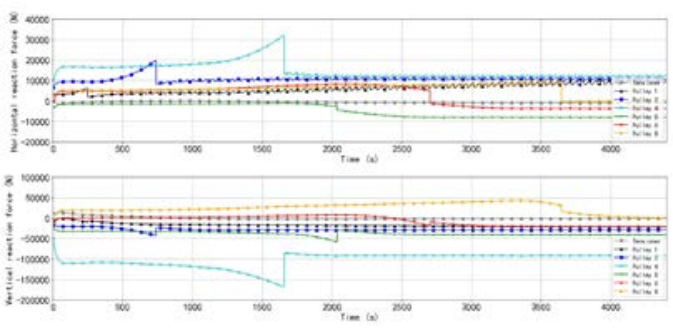

Fig. 7. Curves of horizontal and vertical reaction force of pulley (point $\mathrm{O}$ ) versus time (traction speed $\mathrm{v}=1.39 \mathrm{~m} / \mathrm{s}$, traction mode: 1 pulls 2 ) 


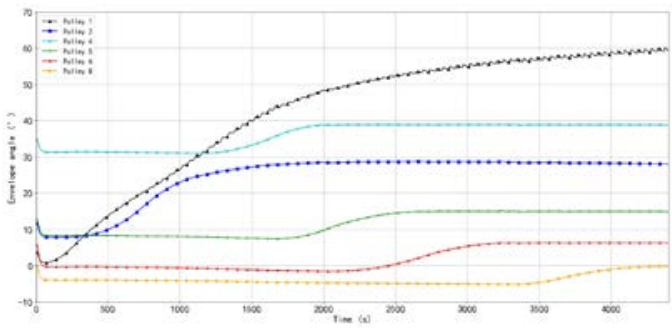

Fig. 8. Curves of envelope angle of the conductor passes through the pulley versus time (traction speed $\mathrm{v}=1.39 \mathrm{~m} / \mathrm{s}$, traction mode: 1 pulls 2 )

3) 1 pulls $4, v=1.39 \mathrm{~m} / \mathrm{s}$

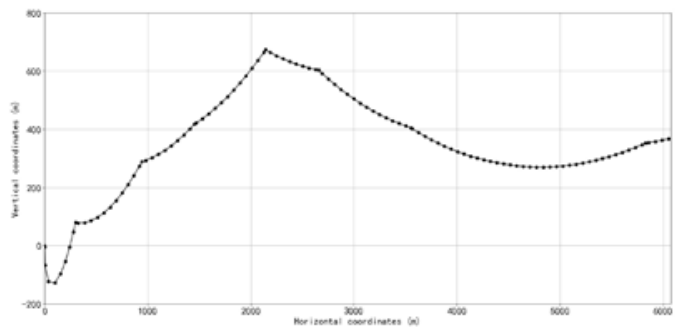

Fig. 9. Configuration of wire rope pulls conductor (traction speed $\mathrm{v}=$ $1.39 \mathrm{~m} / \mathrm{s}$, traction mode: 1 pulls 4 )

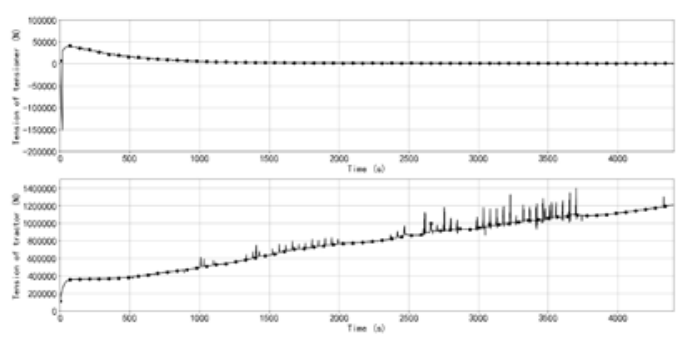

Fig. 10. Curves of tension of tensioner (point A) and tractor (point B) versus time (traction speed $\mathrm{v}=1.39 \mathrm{~m} / \mathrm{s}$, traction mode: 1 pulls 4 )

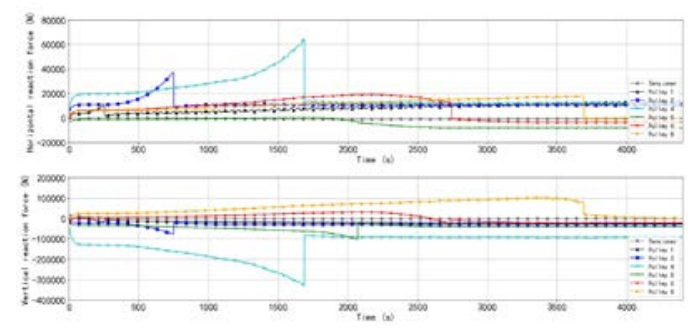

Fig. 11. Curves of horizontal and vertical reaction force of pulley (point $\mathrm{O}$ ) versus time (traction speed $\mathrm{v}=1.39 \mathrm{~m} / \mathrm{s}$, traction mode: 1 pulls 4 )

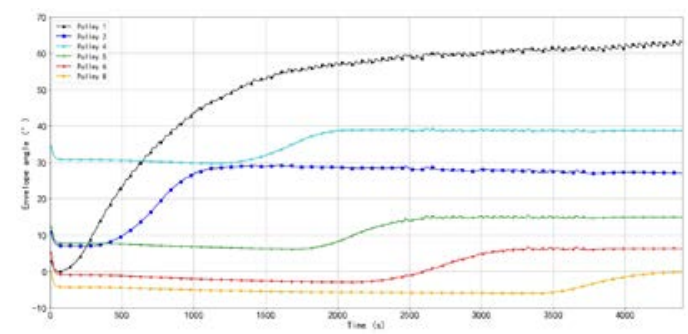

Fig. 12. Curves of envelope angle of the conductor passes through the pulley versus time (traction speed $\mathrm{v}=1.39 \mathrm{~m} / \mathrm{s}$, traction mode: 1 pulls 4 )

The maximum value of tension of tensioner (point $\mathrm{A}$ ) and tractor (point B) are shown in table III, the maximum value of horizontal and vertical reaction force of pulley (point $\mathrm{O}$ ) and envelope angle of the conductor passes through the pulley are shown in table IV. The tension of the tensioner (point A) decreases gradually with the increase of time after reaching the peak at the initial moment, and the final value tends to zero. The tension of the tractor (point B) increases gradually with the increase of time. When the traction speed $v=1.39 \mathrm{~m} / \mathrm{s}$, the more conductors pulled by wire rope, the smaller the peak tension of tensioner (point $\mathrm{A})$, the larger the variation range of the tension of the tractor (point B), and the final tension value of the tractor (point B) increases linearly with the number of conductor pulled by wire rope. When the traction speed $v=0.695 \mathrm{~m} / \mathrm{s}$, the tension of the tensioner (point $\mathrm{A}$ ) and tractor (point $\mathrm{B}$ ) decreases with time.

TABLE III. MAXIMUM VALUE OF TENSION OF TENSIONER (POINT A) AND TRACTOR (POINT B)

\begin{tabular}{|c|c|c|c|c|}
\hline & 1 pulls $1 \mathrm{v}=1.39 \mathrm{~m} / \mathrm{s}$ & 1 pulls $2 \mathrm{v}=1.39 \mathrm{~m} / \mathrm{s}$ & 1 pulls $4 \mathrm{v}=1.39 \mathrm{~m} / \mathrm{s}$ & 1 pulls $1 \mathrm{v}=0.695 \mathrm{~m} / \mathrm{s}$ \\
\hline $\begin{array}{c}\text { Tension of tensioner } \\
\text { (point } A \text { ) } \\
F_{\text {A tension }}(\mathbf{N})\end{array}$ & 90691.49 & 64389.36 & 40997.26 & 65131.51 \\
\hline $\begin{array}{c}\text { Tension of tractor } \\
\text { (point B) } \\
F_{B} \text { tension }(\mathbf{N})\end{array}$ & 310968.44 & 611827.90 & 1206901.62 & 176785.94 \\
\hline
\end{tabular}

TABLE IV. MAXIMUM VALUE OF HORIZONTAL AND VERTICAL REACTION FORCE OF PULLEY (POINT O) AND ENVELOPE ANGLE OF THE CONDUCTOR PASSES THROUGH THE PULLEY

\begin{tabular}{|c|c|c|c|c|c|c|c|}
\hline & & Pulley 1 & Pulley 2 & Pulley 4 & Pulley 5 & Pulley 6 & Pulley 8 \\
\hline \multirow{4}{*}{$\begin{array}{l}\text { Horizontal } \\
\text { reaction force of } \\
\text { pulley } F_{\mathrm{x}}(\mathrm{N})\end{array}$} & 1 pulls $1 \mathrm{v}=1.39 \mathrm{~m} / \mathrm{s}$ & 8631.73 & 11561.88 & 17232.57 & -8206.93 & 3535.74 & 4720.45 \\
\hline & 1 pulls $2 \mathrm{v}=1.39 \mathrm{~m} / \mathrm{s}$ & 10705.42 & 19643.03 & 31994.93 & -8229.71 & 8379.37 & 8828.05 \\
\hline & 1 pulls $4 \mathrm{v}=1.39 \mathrm{~m} / \mathrm{s}$ & 13876.92 & 36832.60 & 63648.19 & -8416.7 & 19080.54 & 17634.88 \\
\hline & 1 pulls $1 \mathrm{v}=0.695 \mathrm{~m} / \mathrm{s}$ & 4394.04 & 10832.98 & 14846.27 & -8056.05 & 1334.98 & 3029.11 \\
\hline \multirow{4}{*}{$\begin{array}{l}\text { Vertical reaction } \\
\text { force of pulley } \\
\qquad F_{\mathrm{y}}(\mathrm{N})\end{array}$} & 1 pulls $1 \mathrm{v}=1.39 \mathrm{~m} / \mathrm{s}$ & -20622.61 & -30165.54 & -94733.45 & -41403.13 & -21277.19 & 15403.15 \\
\hline & 1 pulls $2 \mathrm{v}=1.39 \mathrm{~m} / \mathrm{s}$ & -22505.60 & -42871.19 & -167504.87 & -57308.01 & -21486.48 & 43154.59 \\
\hline & 1 pulls $4 \mathrm{v}=1.39 \mathrm{~m} / \mathrm{s}$ & -25341.20 & -76231.59 & -326379.38 & -102523.41 & -24444.20 & 101659.37 \\
\hline & 1 pulls $1 \mathrm{v}=0.695 \mathrm{~m} / \mathrm{s}$ & -17111.50 & -28800.87 & -78026.18 & -37698.67 & -27121.94 & 3722.73 \\
\hline \multirow{4}{*}{$\begin{array}{l}\text { Envelope angle } \\
\text { of the conductor } \\
\text { passes through } \\
\text { the pulley } a\left(^{\circ}\right)\end{array}$} & 1 pulls $1 \mathrm{v}=1.39 \mathrm{~m} / \mathrm{s}$ & 55.91 & 28.69 & 38.88 & 15.02 & 6.36 & 0.41 \\
\hline & 1 pulls $2 \mathrm{v}=1.39 \mathrm{~m} / \mathrm{s}$ & 60.01 & 28.78 & 39.03 & 15.16 & 6.39 & 0.091 \\
\hline & 1 pulls $4 \mathrm{v}=1.39 \mathrm{~m} / \mathrm{s}$ & 63.34 & 29.29 & 39.37 & 15.41 & 6.74 & 0.0 \\
\hline & 1 pulls $1 \mathrm{v}=0.695 \mathrm{~m} / \mathrm{s}$ & 41.67 & 34.54 & 43.76 & 20.57 & 13.33 & 4.91 \\
\hline
\end{tabular}


When the conductor passes through the pulley, the horizontal reaction force and the vertical reaction force of the pulley are instantaneously increased to the peak and then decreased, and oscillate smoothly with the increase of time. When the traction speed $v=1.39 \mathrm{~m} / \mathrm{s}$, the more conductors pulled by wire rope, the greater the horizontal reaction force and vertical reaction force of the pulley. When the traction speed $v=0.695 \mathrm{~m} / \mathrm{s}$, the horizontal reaction force and vertical reaction force of the pulley decrease, which shows that the force on the pulley can be reduced by reducing the traction speed.

As the conductor passes through the pulley, the envelope angle reaches its peak value and then tends to be stable. The tower position of pulley 4 has a large relative span and elevation difference with the adjacent tower positions, when the conductor passes through the pulley, the pulley receives the maximum horizontal reaction force and vertical reaction force.

\section{CONCLUSION}

In this paper, the vector finite element method is used to study the variations of tension of tensioner and tractor, horizontal and vertical reaction force of pulley and envelope angle of the conductor passes through the pulley in the continuous tension stringing process of conductor with bending stiffness, which provides a reference basis for equipment selection for the tension stringing construction of mountain terrain with large elevation difference.

\section{ACKNOWLEDGMENT}

This work was financially supported by Science and
Technology Project of State Grid Corporation of China (Research on dynamic evolution algorithms of loose strands of conductor and steering construction technology in tension stringing construction with large turning angle in mountainous areas). The number of the project is 5200201955119A-0-0-00.

\section{REFERENCES}

[1] K.O. Papailiou, Senior Member, "On the bending stiffness of transmission line conductors," IEEE Trans, Power Delivery, 1997, vol. 12, pp.1576-1588.

[2] M. Raoof and T.J. Davies, "Determination of the bending stiffness for a spiral strand," The Journal of Strain Analysis for Engineering Design, 2013, vol. 39, pp.1-13.

[3] Lin J H and Zeng W, "Research on aluminum conductor steel reinforced tension layered characteristics of overhead conductor," Electric Wire \& Cable, 2015, pp. 30-33

[4] F. Francesco and M. Luca, "Mechanical modeling of metallic strands subjected to tension, torsion and bending," International Journal of Solids \& Structures, 2016, pp. 91:1-17.

[5] Jiang W G, "A concise finite element model for pure bending analysis of simple wire strand,” International Journal of Mechanical Sciences, 2012, vol. 54(1), pp. 69-73.

[6] Yu Y, Xu X, Luo Y Z, "Dynamic nonlinear analysis of structures based on the finite particle method," Engineering Mechanics, 2012, vol. 29(6), pp. 63-69.

[7] Liu C, Qin J, Wan J C, Jing W C and Fan C H, "Study on equivalent bending stiffness of $1250 \mathrm{~mm}^{2}$ large section conductor," Materials Science and Engineering, 2019, vol. 562, pp. 940-945.

[8] Huang C Y and Huang C Y, "Calculation on construction of $\pm 500 \mathrm{kV}$ large crossing over Yangtze river in Wuhu under tension stringing," Electric Power Construction, 2003, vol. 24(7), pp. 31-32. 